\title{
Semantics of Complex Sentences in Japanese
}

\author{
Hiroshi Nakagawa Shin-ichiro Nishizawa \\ Dept. of Electronics and Computer lingineering, Yokohama National University \\ c-mail: \{nakagawa, shin \}@naklab.dnj.ynu.ac.jp
}

\begin{abstract}
The important part of semantics of complex sentenec is captured as relations among semantic roles in subordinate and main clanse respectively. However if there can be relations between every pair of semantic roles, thle amomot, of computation to identify the relations that hold in the given sentence is extremely large, In this paper, for semantices of Japanese complex sentence, we introduce new pragmatic roles called obsurver and molvaled respectively to bridge somautic roles of subosdinate and those of main clauses. Hy these new roles constraints on the relations among semantic/pragrnatic roles are known to be almost local within subordinate or matu clause. In other words, as for the semantics of the whole complex sentence, the only role we should deal with is a molivated.
\end{abstract}

\section{Introduction}

Our aim is to formalize constraints that ane needed to develop a parser based on unilication grammatic (called "UG" henceforth) so that ont parser can deal with variety of types of sentences in Japanese. How cver just parsing syntactically is not cnought for matiomal language understanding. One important and necessary task to be done, when a parser processes it discourse in Japancse, is the so called toro andiphorat resolution. All of syntactic, semantic, and pratsmatic constraints are to be involved to resolve zero anaphora. Of course, some of omitted pronouns are syntactically resolved. For instance, VP' with sullix to is not regarded as a clause but a comjunct VP. 'Therefore the subject of the VP' with $t o$, which is possibly onitied from surface, should corefer with the sulject of the sentence. Ono example is

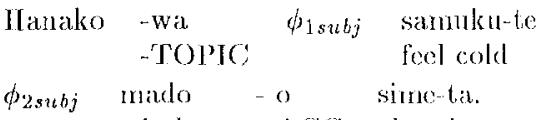

$$
\begin{aligned}
& \text { window - ACC closed. }
\end{aligned}
$$

'Itanako felt, cold and closed the window.' where both of zero subjects $\phi_{1 s u b j}$ and $\phi_{2 s u b j}{ }^{1}$ refer to the sentential topic Manako ${ }^{2}$. In this example, one of the possible acconnts for this interpretation is the following. Kero subject of te phrase is [+ amaphoric, + pronominal ] or PRO in GB term [Sells 85]. As the result, $\phi_{1 \text { subj }}$ is controlled by the subject $\phi_{2 s u b j}$ of the main VP, which is also zero sub. ject. $\phi_{2 s u b j}$ is, in Cils term, [ - maphoric, + pronominal ] or pro. The sentential topic llanako is the only possibte antecedent of this \%ero stulyect in this exanple. However, in complex sentences, things are quite diflerent. Consider the following sentence.

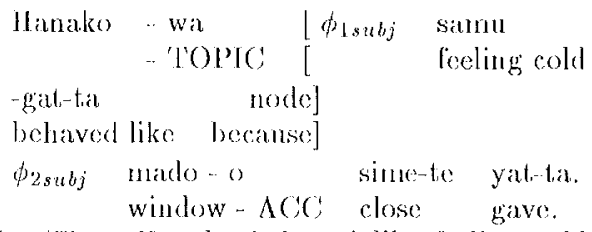

I. 'Since llanako behaved like feeling cold, I closed the window.'

2. 'Since I behaved like feeling cold, Ilanako closed the window.'

If contextually we can hake only Hauako and the speaker of this sentence as candidates of antecedent of $\phi_{1 s u b j}$ or $\phi_{2 s u b j}$, intuitively the following two incerpretations are equally likely.

a. $\phi_{1 s u t j}=$ Ilanako, $\phi_{2 s u t j}=$ speaker

b. $\phi_{1 s u b j}=$ speaker, $\phi_{2 s u b j}:-=$ IImako

'Therefore $\phi_{1 s u b j}$ and $\phi_{2 s u b j}$ are both pto. In fact this fact is well known among o d apanese linguistis, i.e. [Sells 85, 'lakubo 87]. As a result, zero anizphorat resolution of complex sentence is not only to be done syntactically, but also to be done pragnatically and/or semantically. One of the promising candidate for this is the centering, theory [Brenuan ot al 87 , Walker 90]. 'To apply the centering theory that is originally for a secuence of sentences, namely discourse, we regard the subordinate clause and the main clanuse as a segment of discourse respectively. Moreover Hamako who is marked by 'wa' is regarded as the topic for these two clauses. Then, the topic

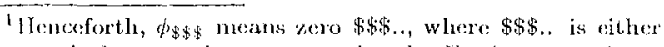
grammatical, semantic or pragmatic role. For instance, $\phi_{s u b j}$ means zero subject, dagt means zero ayent, $\phi_{\text {cxp }}$ means zoro caperienecr, and so forth.

'TIanako' is a typical girl's uame.
} 
Hanako is the strongest candidate for the backward center of the subordinate clause. 'Therefore the backward center of the subordinate clause is Ilanako, and consequently zero subject $\phi_{1 s u b j}$ refers to Hanako. By the same way als the subordinate clause case is dealt with, the zero subject of the main clause $\phi_{2 s u b j}$ is known to refer to Ilanako, too. 'This result is neither interpretation a nor $\mathbf{b}$ shown above. Another candidate is the property sharing thoery [Kancyama 88]. In her theory, since the both of zero subjects share the subjecthood, both of them finally are known to refer to Hanako that is the topic for both of these clauses. Therefore the property sharing theory also fails to account for the intuitive interpretations.

Then we shift our attention to more microscopic one, in which, roughly spoaking, the important part. of semantics of complex sentence is formalized as relations among semantic roles that appear in the main clause or the subordinate clause. At the first glance, the constraints about these relations are not, local in terms of main or subordinate clauses. In other words, semantic roles that appear in subordinate clause and semantic roles that appear in the main clause seem to be directly constrained by the constraints of complex sentence. However, looking more carefully, wo find that the constraints of subordinate clause and the constraints of main clause are represented as local constraints by introducing the new notion of molivated which is characterized as a person who has enough reason to act as the main clause describes. More precisely, molivaled is one of the pragmatic roles that appear in a subordinate clause, and the constraints in subordinate clause are stated as identity relations between motivaled and other semantic/pragmatic roles appoaring in subordinato clause. Therefore these constraints are local in subordinate clanse. The constraints in main clanse are stated as identity relations between motivaled which comes from subordinate clause, and other semantic roles appearing in main clause. Therefore in understanding the main clause we don't have to be care about semantic/pragmatic roles in subordinate clause other than a motivated. In this sense, the constraints in the main clause can be treated as almost local constraints of the main clause.

The next question is how to represent the semantics of complex sentence in feature structure( called FS henceforth). For this, wo should write down the constraints about these relations anong somantic/pragmatic roles in a feature structure formalism. Due to the space limiation, in this paper we mainly pursue the constraints about semantic feature structures.

\section{Hierarchical Structure of Complex Sentence}

We pay our attention to the general structure of Japanese utterance which is helpful to represent semantics of complex sentence. Several Japanese linguists have already proposed the general structure of Japanese utterances [Mikami 53, Minami 74, Takubo 87, Gunji 89]. Mikami categorized clauses into three classes, namely 'open', 'semi-open' and 'closed.' 'L'his categorization indicates how freely the content of clause interacts with the outside of clause. For instance, they are categorized by the degree of possibilities of coreference between zero pronouns inside the subordinate clause and nominal or topic that appear in the main clause. Following Mikann's iclea, Minami proposed four levels, namely level $\Lambda, B, C$ and $\mathrm{D}$ which correspond roughly to VP, proposition, sentence without communicalion mood and utterance which takes into accomt, a hearer, respectively. [Takubo 87] divided level $\Lambda$ into two levels. One of them corresponds to $\mathrm{VP}$, the other corresponds to $\mathrm{VP}+$ a certain kind of subject. which is called "objective subject." Gunji proposed the more detailed structure, in which starting from predicate, say, verb and adjective, objects, voice, subject, ispect, tense, modality, topic and mood are or might, be sequentially added to make an informationally more fulfilled sentence component. Finally, it ends up with an utterance. In Gunji's structure, some node can have more than two daughter nodes to make more complex sentence. Following them, the structure of the so called (cluase level) complex sentence is the following shown in lig. 1 .

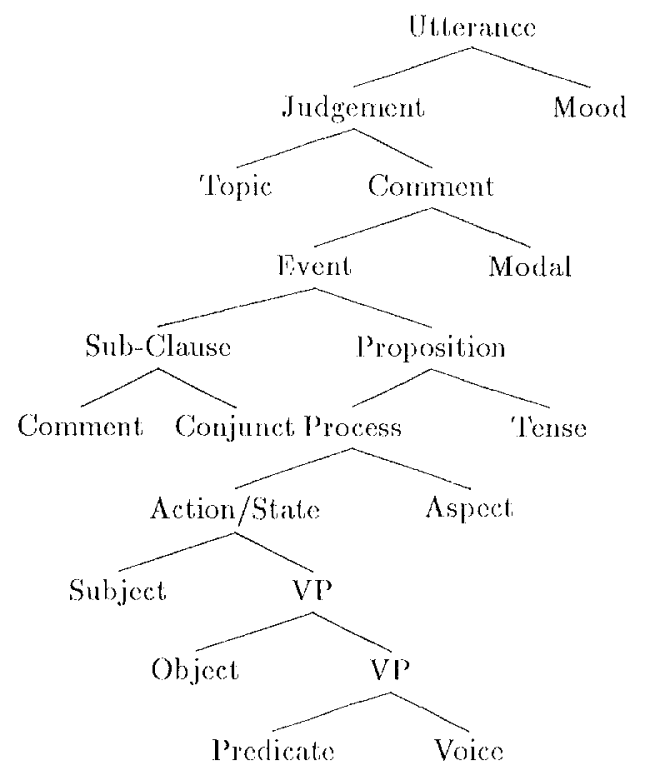

Figuro.1: The hierarchical structure of Japanese utterances

In Pig.1, Sub-Clause and Conjunct mean subordirate clause and conjunctive particle respectively. Note that Fig.1 represents not only the hierarchical structure but also the word order of a complex sentence in Japanese. The structure is almost the same as Gunji's structure except for explicitly showing complex proposition, subordinate-clause 
and conjunctive-particle that are newly added to deal with complex sentences. Note that, 'Comment' appearing in 'Sub-Clause' las the same structure as 'Comment' appearing just bolow 'Judgement,. 'T'hat is to say, 'Comment.' is recursively defined. However., in practice, the more the level of depth of recursively appearing 'Comment' is, the less comprehensible the sentence is

\section{Subordinate Clause}

In this section, at first we show the predicate categories used in the subordinate clanses that wo deal with in this paper, in 'lable l. In each category of $2,3,4,5$ and 6 , exists there a person who is alfected by the situation described by the subordinate clanse. On the contrary, in ategory 1 , there is not necessarily an explicit affected porson. In our theory, this affected person plays a key role for semantics of complex sentence. As the result, in general we camot derive a useful result for calegory 1 in our theory. Therefore we dom't deal with eategory $l$ in this paper.

At this moment, we should explain the nature of the so called subjective predicate montioned in Ihable.1. In short a subjective predicate describes the experiencer's inner state which call oxclusively the known by the experiencer him/herself.

Next we focus on verbal suffix garte l'irstily wo show gara's syntax. Gara is the present form and its root form is gar. Therefore inflections are as follows: gar-re,gar-i, etc. In addition, garn has an allophonic root form gat and, gat-la(past-forn), gatleiru(progressive form) and so on are derived from gat. Some of these forms will appear in our examples. Next we talk abont the semantics of garm. Garu roughly means "show a sign of" or "behave like .ing" [O Jhye 75]. Also in [1'almer 86] ils semantics is informally explained, however our proposal is to formalize garu's somanties in UG or more generatly in computational linguistics. for this, first of all, we introduce a new pragmatic role called observer.

Definition 1 (Obscrver) observer is a person who directly observes or is indiredly informed the sitnation described ty the proposilion part. Therefore an observer has a certain coidence to be convinced that that sitation actually happens.

\begin{tabular}{|c|c|}
\hline 1 & non-subjective predicate \\
\hline 2 & sulbjective verl \\
\hline 3 & subjective adjeclive withoul verbal sullix garn. \\
\hline 1 & subjective anljective with verbal sulfix garu. \\
\hline 5 & $\begin{array}{l}\text { verb + langru } \\
\text { (behave ass s/he wants to "verb") }\end{array}$ \\
\hline 6 & $\begin{array}{l}\text { lamsitive passive and intransitive passive } \\
\text { (adversily passive). }\end{array}$ \\
\hline
\end{tabular}

Table 1: Predicate Categories
Although this notion of observer shares a large part with PIVO'T of [icla-Sells 88], our notion of observer is introduced only by garu. 'Therefore it is much nalrower notion. As you will see later, this newly introduced role is playing a key role which bridges seruantic roles of subordinate clause to semantic roles of main clanse.

As for an observer introduced by garu, one of the widely known consequence about the nature of subjective predicate is the following. In a sentence, if a subjective adjective is used without being followed by a verbal suffix garu, the experiencer of the subjective arljective strould be the speaker of the sentence.

I'tre next. thing we should do about a newly introduced notion of observer is to make clear the way to deal with it in l'S. First of all, in our IS, a scmantic content:SLM is basically a soa (state of affair) form of situation semantics. However we use semantic role like "agent", "patient", "experiencer", and so on, ats argunent roles of soa. Since an observer observes the situation which is characterized by a soa, if we know that there exists an observer, the observed soa is cmbedded in observing situation, which, in turn, is embedeled in the whole semantic content. In this sense, the observed soa's argument role is observed. But as far as we have no confusion, we omit role nane 'olserved' henceforth. A typical schema of SWM of FS of this type is the following. Note that we use garu as a value of the relation fature meant by 'rol.' 'The Euglish gross of this relation garu is 'observe.'

(3) SEM $=\left[\begin{array}{l}\text { rel: } g a r^{\prime \prime} \\ \text { observer:[o] } \\ \text { soa: }\left[\begin{array}{l}\text { rel:R } \\ \text { agent:[a] } \\ \text { experioncer:[o] } \\ \text { patient:[p] } \\ \ldots\end{array}\right]\end{array}\right]$

Now we explain the semantics of clause which comsists of subjective adjoctive with garm or ta-garu, that are in categories 4 and 5. 'These categories' forms are " $\phi_{e x p}$ P'garu" or its past, form " $\phi_{e x p} P$ g'at-la", where $P$ ' is a subjective adjective (calegory 4 in Thable.1) or is a verb followed by tangar (calcgory 5 in 'Table.1), and $\phi_{\text {exp }}$ is the experiencer of $\mathrm{P}$ which is possibly zero. In these categories, there exist observers who are not the experiencer of $\mathrm{l}^{3}$, and observe that experience. 'The SHM feature of " $\phi_{\text {casp }}$ I'g;arr/gat-tia" is the following.

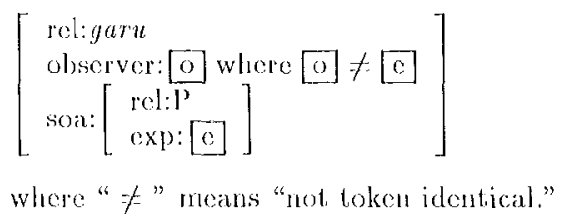

In our l'S, coustraints for tokens like o are written with "where" as shown in this lis. Since constraint satisfaction method in UG has been and is developed by many researchers recontly i.e. ['I'suela 91], 
our theory will be able to be implemented in systems like theirs.

If the sentence finishes just after "garu/gat-ta", the important points are 1) an introduced observer is the speaker, and consequently 2) the experiencer cannot be the speaker. If a clause with "garu/gatta" is a subordinate clause, the experiencer camnot be identified with a semantic role corresponding to the subject of main clause or higher clause.

As for category 2, subjective verbs like "kurusimu" (feel sick) and "kanasimu" (ficel sadncss) that describe subjective and/or emotional experience in verb form, are used. Like the case of garu, an observer who observers the experience can be introduced. However this observer is not obligatory. Therefore unlike the "garm/gat-ta" casc, the experiencer also can be an obligatory semantic role of higher clause as well as the speaker.

\section{Complex Sentence}

\subsection{Feature Structure}

According to the hierachical structure of Japanese sentence shown in Fig.1, the essential part of hierarchical structure of the following sentence (5) is shown in Fig.2. In this figure, the structure just below each proposition is replaced with the corresponding parts of sentence.

$$
\begin{aligned}
& {\left[\begin{array}{lll}
\phi_{e x p} & \text { samil } & \text {-gat-tal }
\end{array}\right.} \\
& \text { [ feel cold behaved like } \\
& \text { node] } \phi_{a g l} \text { mado-o sime-ta. }
\end{aligned}
$$
'Since $\phi_{e, x_{p}}$ behaved like feeling cold, $\phi_{a g t}$ closed the window.'

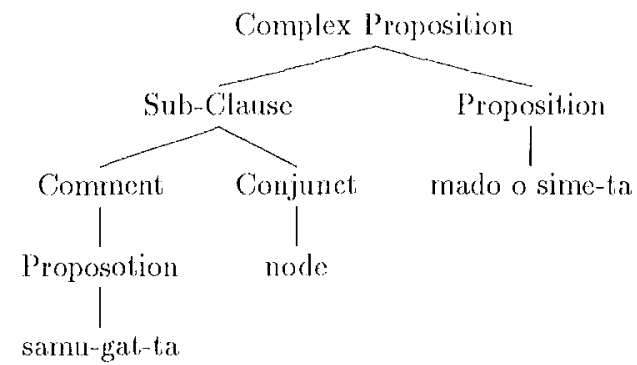

Figure.2 : Hierarchical structure of (5)

Basically the cmbedding structure of FS corresponds to the hierarchy shown in the hierarchical structure Fig.1. To grasp the image of the relation between a lierarchical structure and the corresponding $\mathrm{FS}$, we show an example of $\mathrm{FS}$ of the above complex sentence (5) analyzed based on this hierarchical structure in the following. 'This IS is the result of the unification between the Hs of subordinate clause and main clause, where the contents of syntactic feature IILAD, narnely syn is omitited.

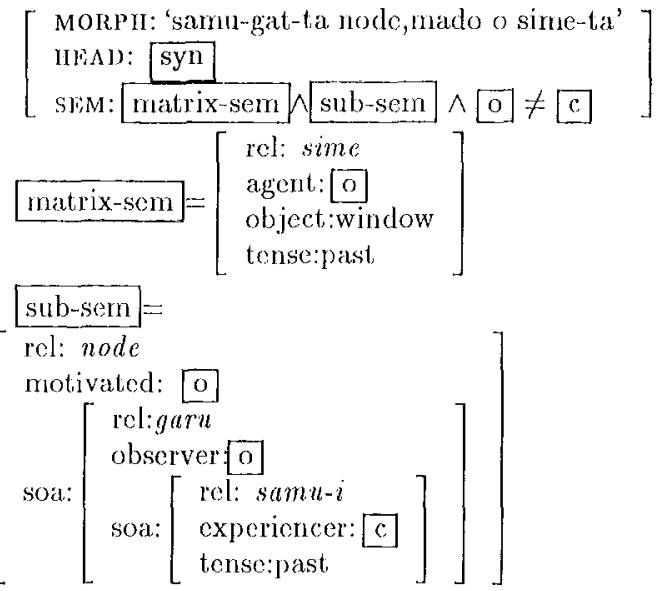

where English grosses of relation name is the following: sime:'close', node:'because', samu-i:'feel cold'.

The key point of the scmantics of complex sentence is the role motivated that appears in sub-sern which corresponds to the content of the subordinate clause. 'The role motivated is the link between the content ol subordinate clause and the main clause. Semantically motivated is characterized as the following.

Definition 2 (Motivated) Molivated is a person who is affected by the situation described by the subordinate clause deeply enough to feel or act as the main clause describes.

The important and indispensable part of semantics of complex sentence is, roughly speaking, the relation belween a subordinate clause and the main clause. But if you look more closely, this relation is actually the rolations among semantic/pragmatic roles appearing in the subordinate clause and those appearing in the main clause. 'The newly introduced role of motivaled gives the most important che for this relation. Therefore, in the rest of this paper, our cflort will be concentrated into whom a motivated refers to. More precisely, in $\mathrm{NS}$, our main concerns are which semantic role in the SEM of subordinate clause the motivated can or cannot be unified with, and which semantic role in the SEM of main clause the motivaled can or cannot be unified with.

\subsection{Constraints}

In this subsection, we propose the constraints on complex sentence. For this, at, first we categorize the relations between subordinate clause and main clause based on their semantics. They are divided up to many types of complex sentence. We show the nost important and typical types in Table.2, where $S C$ and MC mean 'subordinate clause' and 'main clause' respectively. In this table, the first column is for a name of sentence type, the second columm indicates a rough meaning of the relation between 


\begin{tabular}{|c|c|c|}
\hline type & $\begin{array}{l}\text { outine meaning of } \\
\text { conplex sentence }\end{array}$ & Japanese conjuncts \\
\hline 1 & SC callses MC & node, kara \\
\hline 2 & Although SC, MO & $\begin{array}{l}\text { Moni, ga, herodomo, } \\
\text { lemo, i-te, } \\
\text { i-lubu, i-nagara }\end{array}$ \\
\hline 3 & If SC then $\mathrm{MC}$ & Ta, nara, tara, reba \\
\hline 4 & $\begin{array}{l}\text { When/after/before } \\
\text { ete SC, MC }\end{array}$ & $\begin{array}{l}\text { loki, ato, } \\
\text { mae, otc. }\end{array}$ \\
\hline
\end{tabular}

Iable 2: Clause Adjuucts

subordinate clanse SC and main clanse MC of complex sentence, and the third columm shows dapanese conjunctive particles used to represent a type of contplex sentence in the sanne row.

Three VP adjuncts, te, tulu, and nagara, are usually used to express events ocurring simulaneonsly. llowever, if they are used with aspectual suflix $i$ which means perfective, for instince i-nagara, they are regarded as clause conjuncts and are to be inter preted as 'although' [Minami 74]. We don't deal with type 4 , because a temporal adverbial clause just de scribes an event that oceurs betore, simultaneously or after another cvent, which is described by the main chanse. 'Therofore generally we don't expect essential information for relations anong semantic roles appearing in adverbial or main clatse from this type of sentence.

Now we focus on type 1,2 and 3 , where a mo. tivated plays the key role in the constraints. Tu Table. 3 we show the constratints that say which se. mantic/pragnatic role of subordinate clanse can be a motivated. 'Tible 4 shows which semantic role of' main clause can be unified with the molivated. In these tables, the first columm of the first row is for constraint names, the second column shows a sot of sentence types for which the constraints shown in the second row apply. 'The third columu of 'lable.3 shows predicate patterus of subordinate clause, and the thirel column of 'Table. s shows semantic cate. gories of predicale of matin clause. For them, constraints written in the second row apply. Note that all of these constratuts in 'bable. is are local in a subordinate clanse, becanse both sides of a of constraints are roles of subordinalo clanse. In case of sulujec live adjective without garu, the constrant 'molivated $=$ experiencer' holds also for type I except for the case where directionally auxiliary verb "yauru(give)", "kureru(be given)" are used. Analysis for these cases is one of our future problem.

As for 'l'able.4, stabe* is a state except for the case that. there exists a third party who is a motivaled puts the experiencer into that state. For instance, the experencer is permitted to elo something, by the motivaled. Since in this kind of case things are quite complicated, we omit, it here because of the limited space. Constraints in 'Iable 4 are also local in a main clause because every semantic role that appenes in the righthand side of the constraints is clecined within

\begin{tabular}{|c|c|c|}
\hline name & t.ype & predicatic \\
\hline \multicolumn{3}{|r|}{ constraint } \\
\hline S1 & 1,3 & $\begin{array}{l}\text { subjective adjoctive }+g a r a \\
\text { verb }+a+\text { aru }\end{array}$ \\
\hline \multicolumn{3}{|r|}{ motivaled =: observer } \\
\hline \multirow[t]{2}{*}{$\mathrm{S} 2$} & 2 & $\begin{array}{l}\text { subjective adjective + garu } \\
\text { verb }+l a+\text { garm }\end{array}$ \\
\hline & $1,2,3$ & subjective vorb \\
\hline \multicolumn{3}{|c|}{ molivaled $=$ obscrver $\vee$ expericncer } \\
\hline 53 & 1 & subjective adjective (without garnl) \\
\hline \multicolumn{3}{|r|}{ motivated = expertenecr } \\
\hline $\mathrm{S} 4$ & 2,3 & subjective aljective (withoul $g a r u$ ) \\
\hline \multicolumn{3}{|c|}{ molivated - expenicneer $\vee$ observer } \\
\hline 85 & $1,2,3$ & intransitive passive \\
\hline \multicolumn{3}{|r|}{ motivaled a: ufected } \\
\hline$\$ 6$ & $1,2,3$ & transitive patsive \\
\hline & tivat & $\begin{array}{l}\therefore \text { affected affected exists, } \\
\text { - patient: olherwiso }\end{array}$ \\
\hline
\end{tabular}

where 'nane' means a name of each constraint.

Table 3: Constraints in Subordinate Clanse

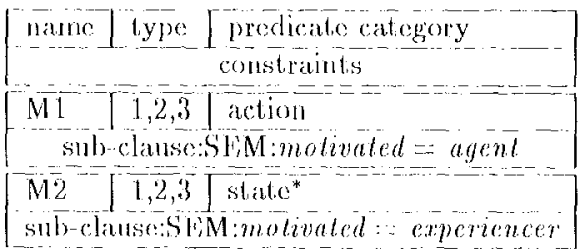

Table 4: Constraints in Main Clanso

the maniu clause. Needless to say, the influence from a subordinate clanse comes only via role motivated.

In the rest of this section we show the examples that exemplify these constraints. ${ }^{3}$

First, we take (5) of type 1. The constraints to be applicd are $\$ 1$ and MI as you know from the contents of subordinate and natu clanse. By combination of SI and MI, zero agent of main clanse: $\phi_{\text {agt }}$ is the observer of the situation deseribed by the subordinate clause, where $\phi_{o x p}$ behaved like feeling cold. 'This intorpretalion coincides with native's intuibion.

look at the following palir of exanple.

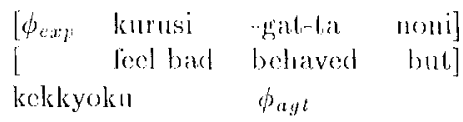

a. lask

kusuri-o nom anakat-ta. modicine- $\Lambda C \mathrm{C}$ drink not PAST

'Althongh $\phi_{e x p}$ behaved like feeling bad, $\phi_{a g t}$ didn't take n medicine at last.,
(7) $\left[\phi_{e x p}\right.$ nokori ta grat-tia 1 stiay want bolaved like nonii] kekkyoku tim oi dasi-1at but. finally forecd out.

3he examples stown below are a lip of iccherg we actut ally analyzed, of course. We gatlore the data alowit native's intuitive interpretation from more than twenty natives around anthors. 
'Although $\phi_{\text {exp }}$ wanted to stay, $\phi_{\text {agt }}$ finally forced him out.'

In both of (6) and (7), the motivaleds of subordinate clause are constrained by S2, namely motivateds can be cither $\phi_{e: r p}$ or the observer of subordinate clause. Constraint M1 says that in both cases, $\phi_{a g t}$ is unified with the motivated. Intuitively in (6), $\phi_{a g t}$ is $\phi_{e x p}$. On the other hand in (7), $\phi_{a y t}$ is the observer. Both of these interpretations comply with constraints S2, and M1.

(8)

$$
\begin{aligned}
& {\left[\begin{array}{ll}
\phi_{1 \exp } & \text { atui node }
\end{array}\right]} \\
& {\left[\begin{array}{ll}
\phi_{2 \exp } & \text { be hot because }
\end{array}\right]} \\
& \\
& \text { be in trouble. }
\end{aligned}
$$

'Since it is hot, I am in trouble.'

Intuitively $\phi_{1 e x p}$ corefer with $\phi_{2 e x p}$. 'This interpretation is expected by constraint $\$ 3$ and M2 that apply in this case. As you know from these examples, our constraints are not strong cnough to identify the antecedent of $\phi_{a g t}$ uniquely, but makes safe interpretations. Moreover disarnbiguation done by these constraints is useful for further inference that will be done with commonsense knowledge or with a special vocabulary like 'kekkyoku(finally)' used in (7).

In case of S5, namely intransitive passive or adversity passive, it is well known, i.e. [Gunji 87] that there exists a person who is affected by the situation described by the passive sentence. An example

\begin{tabular}{|c|c|c|}
\hline$\left[\phi_{a f f e c t}\right.$ & $\begin{aligned} \text { luma - ni } & \sin \\
\text { wife } & \text { be dead }\end{aligned}$ & $\begin{array}{l}-\operatorname{arc} \\
-\mathrm{J} \Lambda \mathrm{SSIVE}\end{array}$ \\
\hline -ta & noni] & \\
\hline -PAST' & but] & \\
\hline$\phi_{e x p}$ & $\begin{array}{l}\text { kanasimi - mo -si } \\
\text { show sadness }\end{array}$ & \\
\hline
\end{tabular}
sentence is the following.

(9)

'Although his wife had gone, $\phi_{e x p}$ doesn't show a bit of sadness.

The semantic role of this affected person, in (9) zero role: $\phi_{\text {affect }}$ whose wife was dead, is an affected. The intuitive interpretation that $\phi_{e x p}=\phi_{a j s e c t}(=$ motivated), is expected by our constraints: $S 5$ of 'Table. 3 and M 1 of Table.4. On the contrary, in case of $\mathrm{S} 6$, namoly transitive passive, generally we don't have an affected. However in some context, a transitive passive form may require the role affected which is inherent to adversity passive. For instance,

$$
\begin{aligned}
& \phi_{a f f e c t} \text { saihu - ga flustum } \\
& \text {-are }-t a \\
& \text {-PASSIVE -PASTI } \\
& \text { ' } \phi_{\text {affect }} \text { 's wallet was stolen.' }
\end{aligned}
$$

In this case, a person whose wallet was stolen is not explicit but regarded as an affected. Another case having an affected is that a relational nom is the subject of transitive passive. Then a person who

\begin{tabular}{|c|c|c|c|}
\hline kobum & $-g a$ & yar & -are \\
\hline [ henchrran & -SUBJ & attack & -PASSIVE \\
\hline $\begin{array}{l}-\mathrm{ta} \\
-\mathrm{P} \Lambda \mathrm{S} T\end{array}$ & $\begin{array}{l}\text { node ] } \\
\text { because] }\end{array}$ & & \\
\hline $\begin{array}{l}\text { sikaes } \\
\text { retalia }\end{array}$ & nii & & \\
\hline
\end{tabular}
is in the relation expressed by the relational noun is thought to be affected by that situation, too. Here we take 'mother', 'father', 'daughter', 'son', 'supervisor', and so forth as a relational noun. $A$ couple of example sentences are the following.

'Since his henchman was attacked, the boss retaliated.'

$\begin{array}{llll}\text { [ kobun } & \text {-ga } & \text { yar } & \text {-are } \\ \text { [henchman SUBJ atide -PASSIVE } \\ \text {-tar noni] } \phi_{\text {agt }} \text { te-o komancite-iru. } \\ \text {-PAST but] } & \text { did nothing. }\end{array}$

'Although his honchman was attacked, the boss didn't retaliate.'

$\phi_{a g l}$ who retaliated (11) (or didn't retaliate (12)) has a certain relation between the henchman who had been attacked. For instance, $\phi_{\text {all }}$ may be the boss of that henchman. In (11), since constraint $\mathrm{S} 6$ of Table. 3 and M. 1 of Table.4 apply, $\phi_{a y t}$ is an affected of attacking event described in the subordinate clause. This interpretation coincides with native's intuition.

In sum, with these constraints, a constraint satisfaction process in UG based parsing can be done locally and consequently very efficiently. In other words, primarily a constraint satisfaction process of a subordinate clause can bo done within the analysis of subordinate clause, and that of the main clause can be done within it except for using motivated whose value has already been constrained in the subordinate clause.

\section{Related Works and Conclu- sions}

One of the relevant researches to onrs is JPSG that has been developed by Gunji[Gunji 87, Gunji 89] and is further studied by the ICO'l working group. Our focus is a more pragmatics oriented one than JPSG is. Many Japanese linguists have already clone the enormous amount of basic observations and proposed linguistic theories about the phenomena we deal with in this paper [Mikami 53, Kuno 73, Kuno 78, Ohyo 75, Minami 74, Takubo 87, Teramura 84, Teramura 90, Saito 92]. Of course our research is based on their works and observations. In [Ohye 75], it is said that if garu is used in a subordinate clause, the subject of the main clause is not the expericncer of the subordinate clause. In [Saito 92], she says that 1) a cognizer that corresponds to our observer is introduced if garu is used, and 2) if an observer is introduced in the subordinate clause, the mentally responsible person appcaring in the main clause is identical with the observer. In linguistic phenomena, these observations are similar to the 
constraint we propose here. So what is new? 'The answer is that: 1) Wo explicitly state the semantics of complex sentence as the relations among semantic roles. Namely, since we use semantic/pragmatic roles instead of grammatical roles in constraints, our constraints can account for zero ancaphora in a sentence where the main clause is passive where an agent or an experiencer is not necessarily the subject, like the following eximnple.

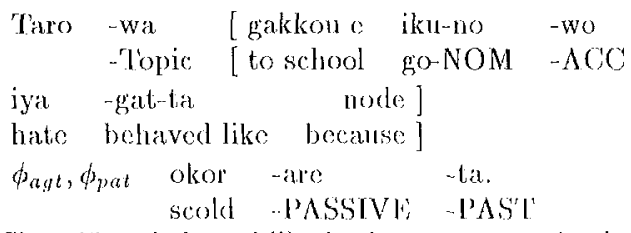

"Since 'laso belaved like hating to go to school, he was scolded.'

where the intuitivo reading is the following: $\phi_{p a t}$, that is zero subject, refers to 'laro, and tagt, that is not the zero subject, refers to 'laro's parents who are the observer and motivated of the subordinate clatse. 2) We formalize this theory in UG formalism, even though the details are omitied due to the space limitation. 3) Wo finct that the constraints of complex sentences are actually local ones. 'This localization of constraint was found hy introducing new pragmatic roles observer and molivated, and is extremely important for efficiency of UG based parsing. 'This localization also makes the proposed constraints be compositional ones, because in the case of decply entbedded complex sentence to identify the referent of ach motivated that bridges between a subordinate clause and its inain clause, the constraints we proposed are resolved with computation confined within cach clause.

Analysis of case in which a directional anxiliany verb i.e. 'yaru', 'kureru' is used is left as the future problem. linally, we implenented a Japanese lauguage understianding system bised on the theory we state in this paper, but due to the space lintitation we will report the detail of implementation in other place in the rear fiture.

\section{References}

[Breman et al 87] Brenman, S., M. Walker Fricelman and (C.Pollard (1987). A Centoring $A_{p}$ proach to Pronouns. 25th Anmual Mecting of $\mathrm{ACL}, \mathrm{pP} .155-162$

[Gumji 87] Gunji, 'T.(1987). Japanese Phase Structure Grammar. Reide], Dordrecht.

[Gunji 89] Gunji,T. (1989). Relevance of the Formalization of phrase Structure Grammar to Mechanical Language Processing. Report of 'Tokutei-Kenkyu, Ministry of Piducalion and Academy
[lida-Solls 88] lida,M. and P.Sells(1988). Discourse lactors in the Binding of zibun. in Japanese Syntax (ed. W.P'oser) CSLI, Stanford

[Kameyama 88] Kaneyama, M. (1988). Japanese Fero Pronominal Binding: Where Syntax and Discourse Moet. in Japanese Syntax (ed. W.Poser) CSTI, Stianford

[Katagiri 91] Katagiri,Y. (1991). Perspectivity and Japanese Rellexive 'zibun'. in CSII Jecture Notes No.26, Situation Theory and its Applications Vol.2, J.Barwise et al cds. pp.425447

[Kuno 73] Kuno, S. (1973). The structure of the Japanese Language. Cambridge, MI'T l'ress

[Kuno 78] Kuno,S.(1978). Danwa no Bumpon. Thaishukan, Tokyo

[Ohye 75] Ohyo,S.(1975). Nitieigo no llikakukenkyu Thashukan, Tokyo

[Saito 92] Saito,R.(1992). Shinjon Jutugo no Goy ouronteki Bunseki (Pragmatic Analysis about, P'sychological Predicates). Nihongogaku, Vol.11, No.6, pp.110 116

[Mikani 53] Mikami,A.(1953). Gendai Gohou Josche. Kuroshio-Shuppan, 'liokyo

[Minami 74] Minauri,li.(1971). Gendai Nilongo no Kouzou. Thishmkan, 'Tokyo

[Palmer 86] P'alnuer, F'.R.,(1986). Mood and Modality, Cambridge University Press, Cambridge

[Sells 85] Sells, P'. (1985). Lectures on Contemporary Syntactic Theories. CSII Stanford

['Takubo 87] Takubo, Y. 'Iongokouzou to Bunnyakinjouhou (Syntactic Structure and Contextual Information. Nihongogaku 1987-5, Meiji-shoin,'Lokyo

['Teraumura 84] 'Jerammra,ll.(1984). Nihongo no sinlakusu to imi II of apanese Syntax and Semanties 1J'. Kuroshio-Shuppar, 'Tokyo

['leranuma 90] J'eranura, H. (1990). Nihongo no sintakusu to imi l[l 'J ajanese Syntax and Scmanties Ill', Kuroshio-Shuppan, 'Tokyo

['T'suda 91] 'I'suda,II,ILasida,K.,Sirai,H. (1989). IPSG P'arser on Constraint Logic Programming. 4th AC, Liuropean Chapter

[Walker 90] Walker,M.,M. licla and S. Cote(1990). Contering in dapanese Discourse. COL IN( $x^{\prime} 90$ 